九州大学学術情報リポジトリ

Kyushu University Institutional Repository

\title{
Cold Consolidation of Ball-Milled Titanium Powders Using High-Pressure Torsion
}

\section{Edalati, Kaveh}

Department of Materials Science and Engineering, Faculty of Engineering, Kyushu University

Horita, Zenji

Department of Materials Science and Engineering, Faculty of Engineering, Kyushu University

Fuj iwara, Hiroshi

Ritsumeikan Global Innovation Research Organization, Ritsumeikan University

Ameyama, Ke i

Department of Materials Science and Engineering, Faculty of Science and Engineering, Ritsumeikan University

http://hdl. handle. net/2324/26391

出版情報: Metallurgical and Materials Transactions A. 41 (13)，pp.3308-3317，2010-12-01. Springer US

バージョン:

権利関係: (C) The Minerals, Metals \& Materials Society and ASM International 2010 


\title{
Cold Consolidation of Ball-Milled Titanium Powders Using High-Pressure Torsion
}

\section{Kaveh Edalati $^{\mathrm{a}, *}$, Zenji Horita ${ }^{\mathrm{a}}$, Hiroshi Fujiwara ${ }^{\mathrm{b}}$ and Kei Ameyama ${ }^{\mathrm{c}}$}

a Department of Materials Science and Engineering, Faculty of Engineering, Kyushu University, Fukuoka 819-0395, Japan

${ }^{\mathrm{b}}$ Ritsumeikan Global Innovation Research Organization, Ritsumeikan University, Kusatsu 525-8577, Japan

${ }^{\mathrm{c}}$ Department of Materials Science and Engineering, Faculty of Science and Engineering, Ritsumeikan University, Kusatsu 525-8577, Japan

\begin{abstract}
Pure Ti (99.5 pct) powders after processing with ball milling (BM) were consolidated to disc-shaped samples with $10-\mathrm{mm}$ diameter and 0.8-mm thickness at room temperature using high-pressure torsion (HPT). A relative density as high as 99.9 pct, high bending and tensile strengths of 2.55 to 3.45 and $1.35 \mathrm{GPa}$, respectively, and a moderate ductility of 8 pct with an ultrafine grained structure are achieved after cold consolidation with HPT, which exceed those of hot consolidation methods. X-ray diffraction (XRD) analysis showed that a phase transformation occurs from $\alpha$ phase to $\omega$ phase during HPT under a pressure of $6 \mathrm{GPa}$ as in bulk pure Ti, whereas no phase transformation is detected after processing with $\mathrm{BM}$ alone. It was confirmed that the strength and ductility are improved by a combined application of BM and HPT when compared with other severe plastic deformation methods applied to Ti and Ti-6 pct Al-4 pct V, so that no alloying elements are required for the achievement of a comparable strength and ductility.
\end{abstract}

\footnotetext{
* Contact e-mail: kaveh.edalati@zaiko6.zaiko.kyushu-u.ac.jp
} 


\section{Introduction}

Considerable interest has been now allocated in processing materials through the application of high-pressure torsion (HPT) not only to produce ultrafine grained materials [1] but also to consolidate powders [2] as well as to achieve pressure-induced phase transformations [3]. In the HPT process, first introduced by Bridgman in 1935 [4], a small thin disc is placed between two massive anvils under a high hydrostatic pressure and intense shear strain is introduced by rotating the two anvils with respect to each other. The HPT as a processing tool for consolidation of powders was first used in 1991 [2] and further developed for the consolidation of metallic powders [5-8], composites [9-22], amorphous compounds [22-28], machining chips [28-30] and very recently for ceramic powders [31]. The HPT process was also applied successfully as a cold consolidation technique without sintering process for ball-milled powders including pure Ni [5], pure Co [7], an Al-Mg alloy [8], Co-based metal-ceramic composites [17, 18] and amorphous powders and chips $[22,23,28]$.

It is well established that processing through the application of ball milling, which is also known as mechanical milling and mechanical attrition, results in a severe grain refinement and a significant hardness increase [32, 33]. In ball milling, first developed by Benjamin around 1966 [32], a powder mixture is loaded into a mill along with grinding balls and the milling is conducted for a period of time. The ball-milled powders are then consolidated into bulk shapes using hot consolidation methods such as hot pressing, hot extrusion, hot isostatic pressing, hot-roll sintering, spark plasma sintering and spray forming followed by a sintering process [33]. In spite of various publications regarding the ball milling of $\mathrm{Ti}$ [35-42], little attention has been paid to the cold consolidation of ball-milled Ti powders through the application of HPT.

Both ball milling and HPT may cause formation of metastable phases due to severe plastic deformation and high applied pressure. It is known that $\mathrm{Ti}$ exhibits a pressure-induced phase transformation from an $\alpha$ phase with the hcp crystal structure to an $\omega$ phase with the simple hexagonal structure during HPT and the $\omega$ phase is retained as a metastable phase at ambient pressure after unloading [3, 43-46]. The $\alpha \rightarrow \omega$ phase transformation in Ti was not detected after processing with ball milling, but instead, there is a report that Ti transforms from the $\alpha$ phase to an fCc phase by ball milling [37, 38].

In this study, thus, ball-milled Ti powders are subjected to consolidation using HPT and the evolutions of mechanical properties and the occurrence of allotropic phase transformations are investigated under two different pressures as a function of the imposed strain.

\section{Experimental Materials and Procedures}

This study used high purity $\mathrm{Ti}$ (99.5\%) powders with a particle size less than $45 \mu \mathrm{m}$ having impurities of O 0.35, C 0.02, N 0.03, H 0.02, Fe 0.03, Mn 0.005, Mg 0.02, Cl 0.04 and Si 0.01 in weight percent. The $\mathrm{Ti}$ powders were subjected to ball milling using a planetary device with a tungsten carbide vial for 50 hours with a rotation speed of $200 \mathrm{rpm}$. Ball to powder weight ratio was 1.8:1 and the material of balls was a high carbon chromium steel (JIS G4805/SUJ2). The vial volume and the balls diameter were $500 \mathrm{~cm}^{3}$ and $10 \mathrm{~mm}$, respectively. To reduce the powder 
contamination and to avoid the atmosphere-induced structural evolution, as reported earlier [33-36], milling was conducted under pure argon atmosphere.

HPT was conducted at room temperature using the ball-milled Ti powders to consolidate to discs with dimensions of $10 \mathrm{~mm}$ diameter and $0.8 \mathrm{~mm}$ thickness under the pressures of 2 and $6 \mathrm{GPa}$ and subsequently introduce strain through either $N=1,4,10$ or 40 revolutions with a rotation speed of $\omega=1.0$ or $0.2 \mathrm{rpm}$. Moreover, additional HPT experiments were conducted under the pressure of $6 \mathrm{GPa}$ for $N=10$ revolutions at a rotation speed of $\omega=1.0 \mathrm{rpm}$ on powder samples without ball milling as well as a bulk sample both with the same purity of 99.9\%. The details of HPT facility was reported elsewhere [46, 47].

The HPT-processed discs were evaluated using Vickers microhardness measurement, bending test, tensile test, optical microscopy (OM), scanning electron microscopy (SEM), X-ray diffraction (XRD) analysis, transmission electron microscopy (TEM) and density measurement. First of all, after processing by HPT, the $10 \mathrm{~mm}$ discs were polished to a mirror-like surface and the Vickers microhardness was measured with an applied load of $200 \mathrm{~g}$ for $15 \mathrm{~s}$ along the radii from the center to edge at 8 different radial directions with $0.5 \mathrm{~mm}$ increments as depicted by cross marks in Fig. 1(a). Second, for bending test, miniature rods with a $0.5 \times 0.5 \mathrm{~mm}^{2}$ square cross section and $9 \mathrm{~mm}$ length were cut from the $10 \mathrm{~mm}$ diameter discs at $1 \mathrm{~mm}$ away from the disc center as illustrated in Fig. 1(a). Three-point bending tests were carried out at room temperature to measure the bending load and displacement. The load was applied in the radial direction and the pressing direction for the samples processed by HPT at $2 \mathrm{GPa}$ for 10 revolutions. The supporting span was $8 \mathrm{~mm}$ and the stroke was controlled at a cross-head speed of $0.5 \mathrm{~mm} / \mathrm{s}$. Assuming linear elasticity, the bending stress, $\sigma$, was calculated from the load and the specimen geometry through the Euler-Bernoulli beam theory [48]:

$$
\sigma=\frac{3 F l}{2 b h^{2}}
$$

where $F$ is the bending load, $l$ is the supporting span $(8 \mathrm{~mm}), b$ is the bending specimen width $(0.5$ $\mathrm{mm})$ and $h$ is the bending specimen height $(0.5 \mathrm{~mm})$. Third, miniature tensile specimens having $1.5 \mathrm{~mm}$ gauge length, $0.7 \mathrm{~mm}$ width and $0.5 \mathrm{~mm}$ thickness were cut from the $10 \mathrm{~mm}$ discs at the position $2 \mathrm{~mm}$ away from the center as illustrated in Fig. 1(a). Since the machining may introduce surface defects and may affect tensile behavior of miniature specimens, the specimens were carefully polished to smooth surfaces following the machining. The appearance of the tensile specimen before testing is shown in Fig. 1(b). Each tensile specimen was mounted horizontally on grips and pulled to failure using a tensile testing machine with an initial strain rate of $2 \times 10^{-3} \mathrm{~s}^{-1}$. To examine the reproducibility of tensile results, tensile tests were repeated twice or three times on different samples processed at the same HPT conditions. Fourth, SEM was performed at $20 \mathrm{kV}$ for observation of fractographs of tensile specimens after failure. Fifth, for XRD, 3mm discs were punched out from the $10 \mathrm{~mm}$ discs at $3.5 \mathrm{~mm}$ away from the center as shown in Fig. 1(a). The 3mm discs were ground and polished mechanically to a thickness of $0.5 \mathrm{~mm}$ smoothly and XRD was performed on these samples as well as on powders after ball milling using the Co K $\alpha$ radiation at 40 $\mathrm{kV}$ and $36 \mathrm{~mA}$ in a scanning step of $0.02^{\circ}$ and a scanning speed of $0.4 \% \mathrm{~min}$. Sixth, for TEM, the 
3mm diameter discs used for the XRD were ground mechanically to a thickness of $0.15 \mathrm{~mm}$ and further thinned with a twin-jet electro-chemical polisher using a solution of $5 \% \mathrm{HClO}_{4}, 25 \%$ $\mathrm{C}_{3} \mathrm{H}_{3}\left(\mathrm{CH}_{2}\right)_{2} \mathrm{CH}_{2} \mathrm{OH}$ and $70 \% \mathrm{CH}_{3} \mathrm{OH}$ at $263 \mathrm{~K}\left(-10{ }^{\circ} \mathrm{C}\right)$ under an applied voltage of $15 \mathrm{~V}$. TEM was performed at $200 \mathrm{kV}$ for microstructural observation and for recording selected-area electron diffraction (SAED) patterns. Seventh, density was measured using the samples processed by HPT at 2 GPa for 10 revolutions including annealed bulk samples for comparison. Three samples were used for these measurements. Both sides of the disc samples were polished to a mirror-like surface and the density, $\rho$, was determined at $298 \mathrm{~K}\left(25{ }^{\circ} \mathrm{C}\right)$ by Archimedes' principle using an electronic balance with an accuracy of $0.1 \mathrm{mg}$ through the following equation:

$$
\rho=\frac{\rho_{w} m_{a}}{m_{a}-m_{w}}
$$

where $\rho_{w}$ is the density of water, $\sim 1$ g.cm ${ }^{-3}$ at $298 \mathrm{~K}\left(25^{\circ} \mathrm{C}\right)$, and $m_{a}$ and $m_{w}$ are the mass of sample in the air and water, respectively. To obtain the average, the density measurement was repeated using three different samples processed at the same HPT conditions.

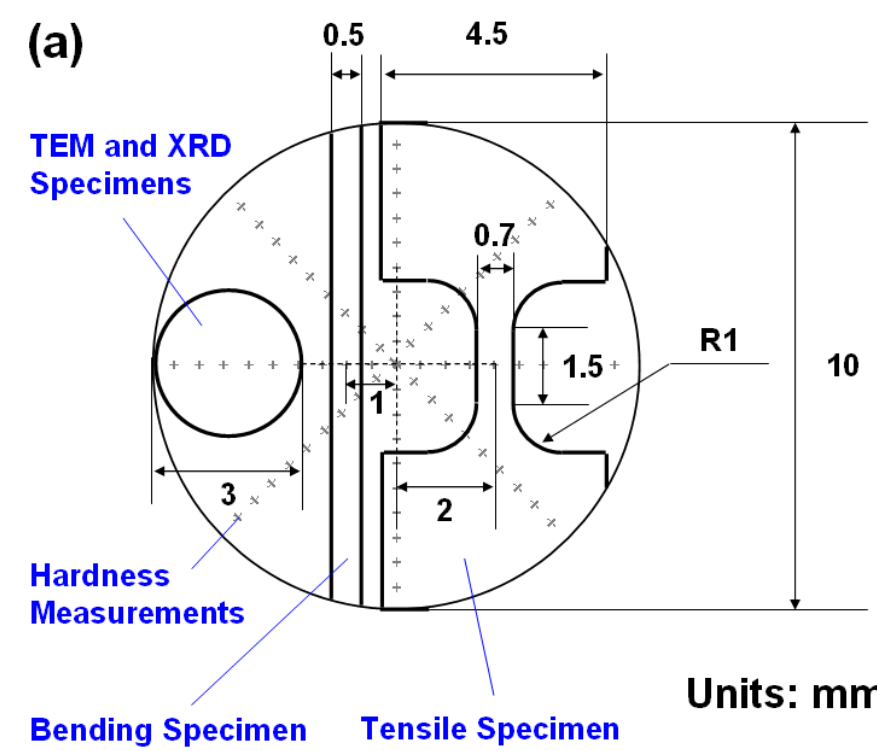

(b)

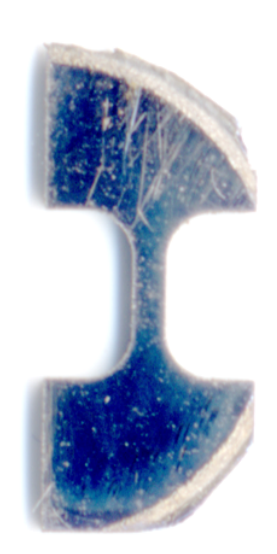

Figure 1. (a) Schematic illustration of HPT disc and positions for microhardness measurements, and dimensions and locations for tensile and bending testing specimens and for TEM and XRD discs and (b) appearance of tensile specimen.

\section{Results}

The measured values of microhardness are plotted in Fig. 2 against the distance from the disc center for $N=1,4,10$ and 40 revolutions under (a) 2 GPa and (b) 6 GPa. It is apparent from Fig. 2 that (1) hardness increases with the distance from the disc center for all numbers of revolutions for both pressures, (2) hardness increases with the numbers of revolutions under $2 \mathrm{GPa}$, (3) hardness increases from $N=1$ to $N=4$ under $6 \mathrm{GPa}$ but the hardness decreases for larger numbers of revolutions from $N=4$ to $N=40$, and (4) for the sample processed under $6 \mathrm{GPa}$ for $N=10$, the hardness level is higher for the rotation speed of $\omega=0.2 \mathrm{rpm}$ when compared with $\omega=1.0 \mathrm{rpm}$. 
All microhardness values in Fig. 2 are plotted against the equivalent strain in Fig. 3. Here, the nominal equivalent strain, $\varepsilon$, was estimated by the equation as [1]:

$$
\varepsilon=\frac{2 \pi r N}{\sqrt{3} t}
$$

where $r$ is the distance from the center of disc, $N$ is the number of revolutions and $t$ is the thickness of disc. It should be noted that the calculation of the equivalent strain through Eq.[3] does not take into account the effect of slippage and thickness reduction during HPT processing because the estimation of these factors is difficult for the form of powders [49, 50].
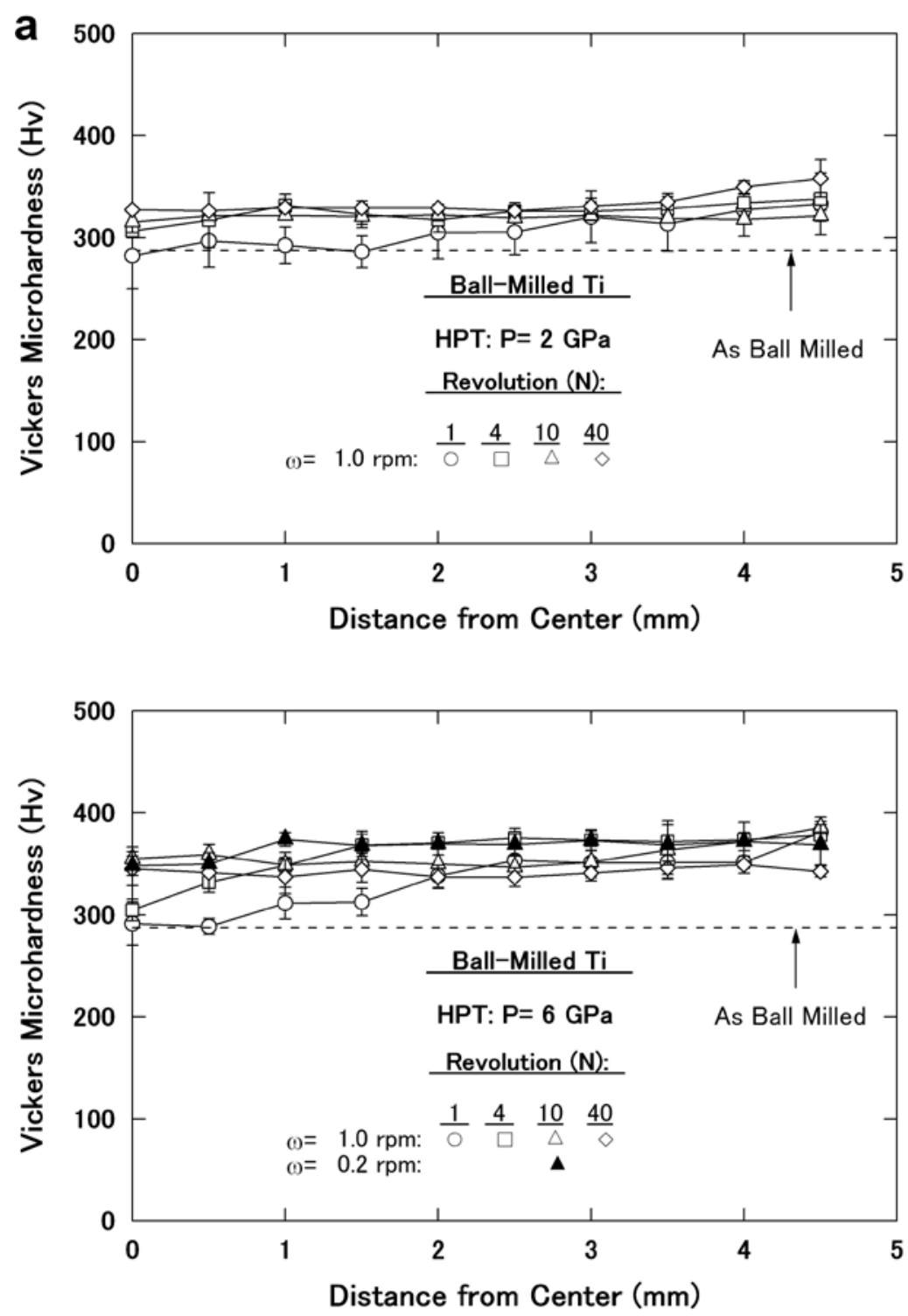

Figure 2. Vickers microhardness plotted against distance from center for disc samples processed after various revolutions under (a) 2 GPa and (b) 6 GPa.

It is apparent from Fig. 3(a) that the hardness increases with increasing equivalent strain at an early 
stage of straining under $2 \mathrm{GPa}$ but appears to saturates to a level of $330 \mathrm{Hv}$ at higher strains. Although, some data points deviate from the delineated curve, the hardness variation with strain for powders consolidated by HPT is similar to that for bulk Ti processed by HPT [46]. Two different saturation levels for hardness appeared for the pressure of $6 \mathrm{GPa}$ as shown in Fig. 3(b): (1) $370 \mathrm{Hv}$ for smaller numbers of revolutions or lower rotation speed and (2) $350 \mathrm{Hv}$ for larger numbers of revolutions and higher rotation speed.
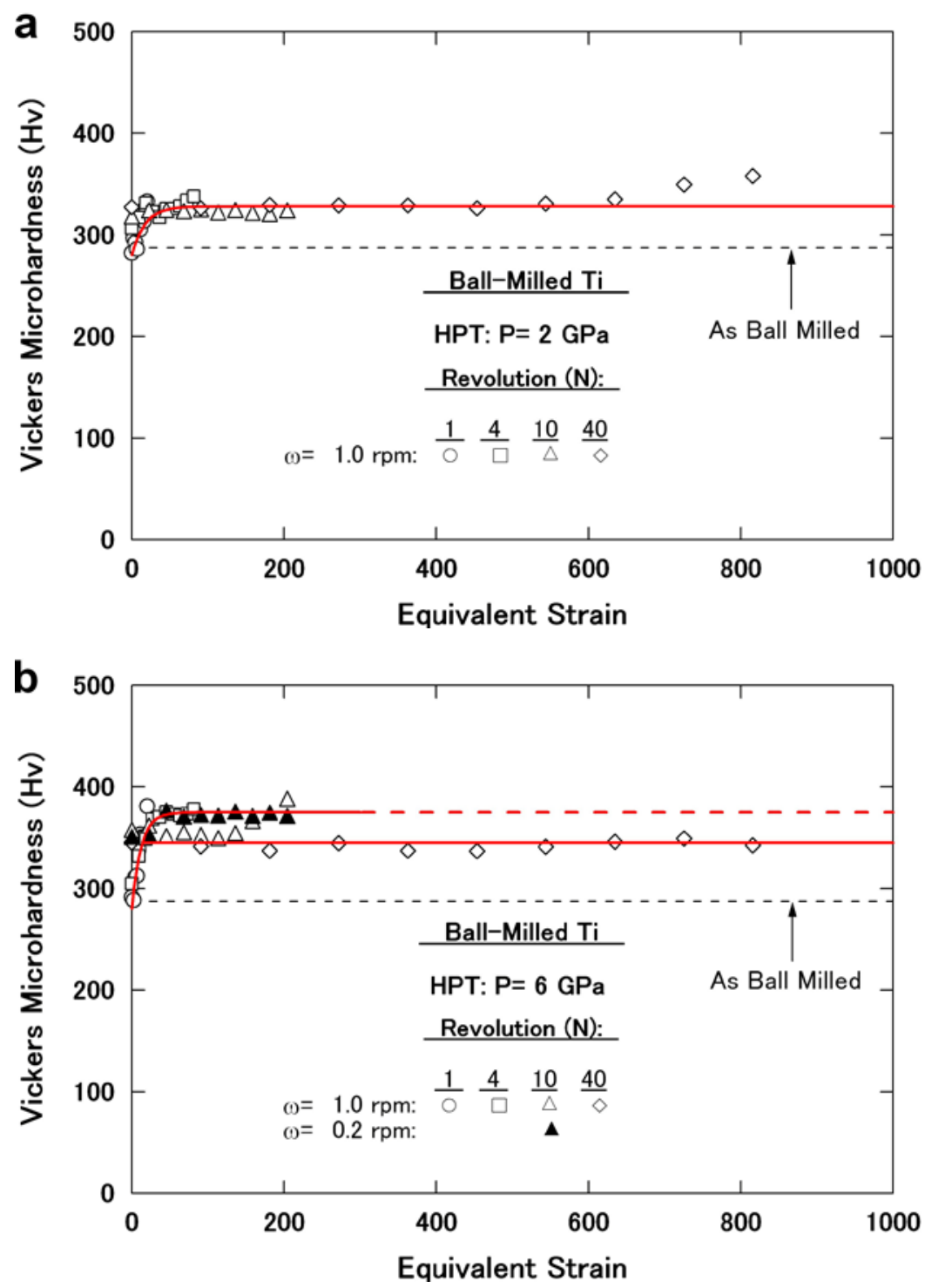

Figure 3. Vickers microhardness plotted against equivalent strain for samples processed after various revolutions under (a) 2 GPa and (b) 6 GPa (all data points shown in Fig. 2).

From the bending tests, the stress-displacement curves obtained with a cross-head speed of $0.5 \mathrm{~mm} / \mathrm{s}$ for the samples processed for $N=10$ under $2 \mathrm{GPa}$ are delineated in Fig. 4 for the radial direction and pressing direction as in the inset. The bending strength and the displacement to failure are large for the sample consolidated with HPT. The bending strength in the radial direction is 
higher than that in the pressing direction but the total displacement to failure shows an opposite trend.

Stress-strain curves for samples processed for different numbers of revolutions under (a) 2 GPa and (b) 6 GPa are delineated in Fig. 5 from the tensile tests conducted at room temperature with an initial strain rate of $2 \times 10^{-3} \mathrm{~s}^{-1}$. For the samples processed under $2 \mathrm{GPa}$, the tensile strength and the total elongation to failure increase from $N=1$ to $N=10$ but the elongation becomes almost zero at $N=40$. For the samples processed under $6 \mathrm{GPa}$, the tensile strength increases from $N=1$ to $N=4$ but remains nearly constant above $N=4$ up to $N=40$, where all specimens except for $N=40$ break elastically. Examination of Fig. 5 indicates that the optimum conditions of HPT to achieve high strength and high ductility are, respectively, $N=40$ under $6 \mathrm{GPa}$ and $N=10$ under $2 \mathrm{GPa}$.

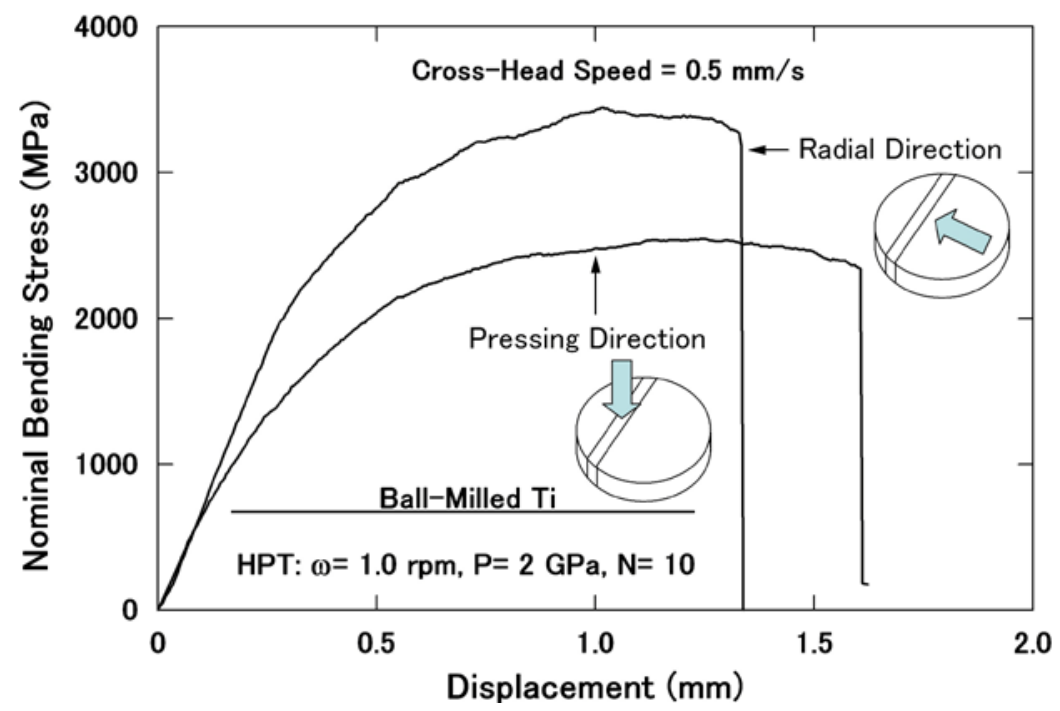

Figure 4. Nominal bending stress versus displacement curves obtained from HPT discs processed for 10 revolutions under $2 \mathrm{GPa}$ in radial direction and pressing direction.

The fracture surfaces after tensile testing of samples processed under 2 and 6 GPa are shown in Figs. 6 and 7, respectively, where (a), (c), (e) and (g) are the overall views of the fracture surfaces corresponding to specimens processed for $N=1,4,10$ and 40. Higher magnification views of the fractographs in (a), (c), (e) and (g) are shown on the right side in (b), (d), (f) and (g), respectively. The sample processed under 2 GPa for $N=1$ fails due to crack propagation as indicated by arrows (Figs. 6(a) and (b)). The fracture surface changes to a vein-like pattern for $N=4$ and some dimples associated with ductility are visible on the fracture surface as marked by arrows (Figs. 6(c) and (d)). The area fraction of the fine dimples increases in the sample processed for $N=10$ (Figs. 6(e) and (f)). The fracture occurs not only on a surface perpendicular to the tension direction but also on a surface having $\sim 20^{\circ}$ slope with respect to the tension direction and the fracture surfaces appear to be smooth and cleaved for the sample processed for $N=40$ (Figs. 6(g) and (h)). All these fractographs are well consistent with the tensile testing results shown in Fig. 5(a). The samples processed under 6 GPa for $N=1,4$ and 10 have a vein-like pattern resulting in brittle fracture (Figs. 7(a)-(f)), although 
some fine dimples are visible in the fracture surface after processing for $N=10$. Fine dimple patters are well developed for the sample processed for $N=40$ (Figs. 7(g) and (h)), indicating that the specimen breaks in a ductile manner. All these features presented in Fig.7 are consistent with the stress-strain curves shown in Fig. 5(b).

TEM microstructures and the corresponding SAED patterns were shown in Fig. 8 for samples after 10 revolutions under (a) $2 \mathrm{GPa}$ and (b) $6 \mathrm{GPa}$. It is shown that the microstructures consist of ultrafined grains with grain sizes in the range of 50 to $300 \mathrm{~nm}$ and an average grain size of $\sim 150 \mathrm{~nm}$. Close examination of the microstructures reveals that there are many dislocations within the grains and most of the grains are surrounded by ill-defined grain boundaries. Whereas some elongated grains are observed in Fig. 8(a), they are rarely seen in Fig. 8(b). These microstratural features are similar to our earlier observations of bulk pure Ti after processing with HPT [46].

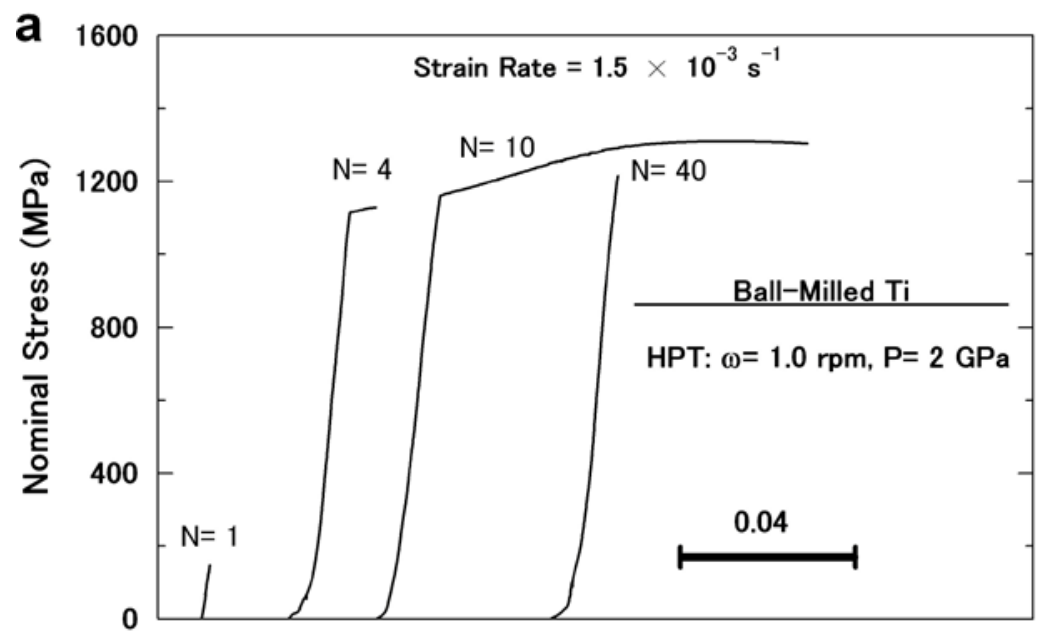

Nominal Strain

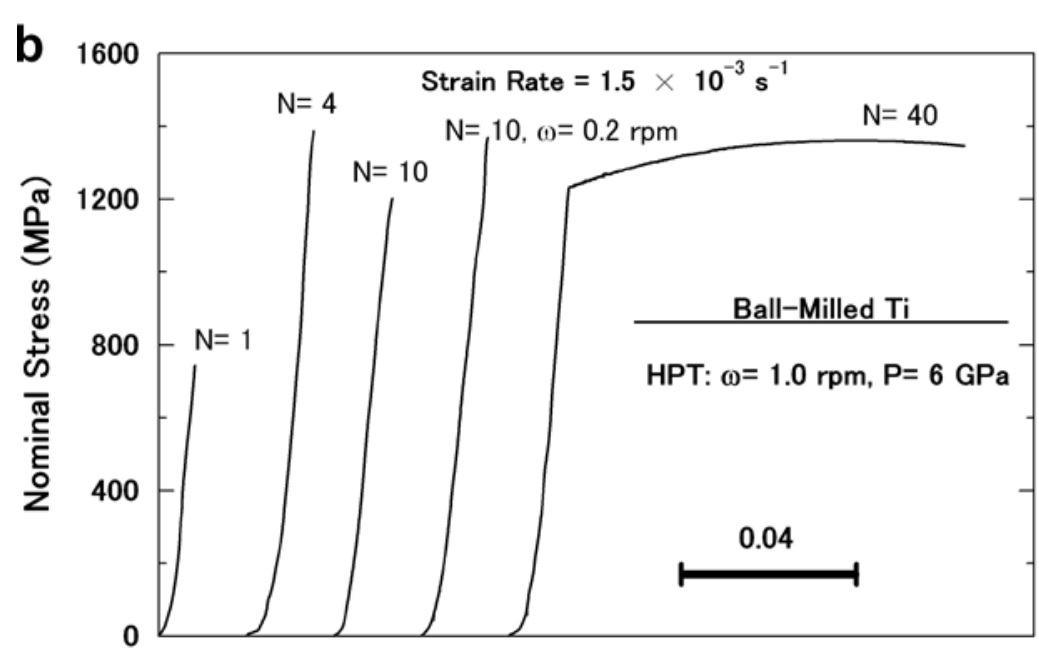

Nominal Strain

Figure 5. Nominal stress versus nominal strain curves for samples processed after various revolutions under (a) $2 \mathrm{GPa}$ and (b) $6 \mathrm{GPa}$. 

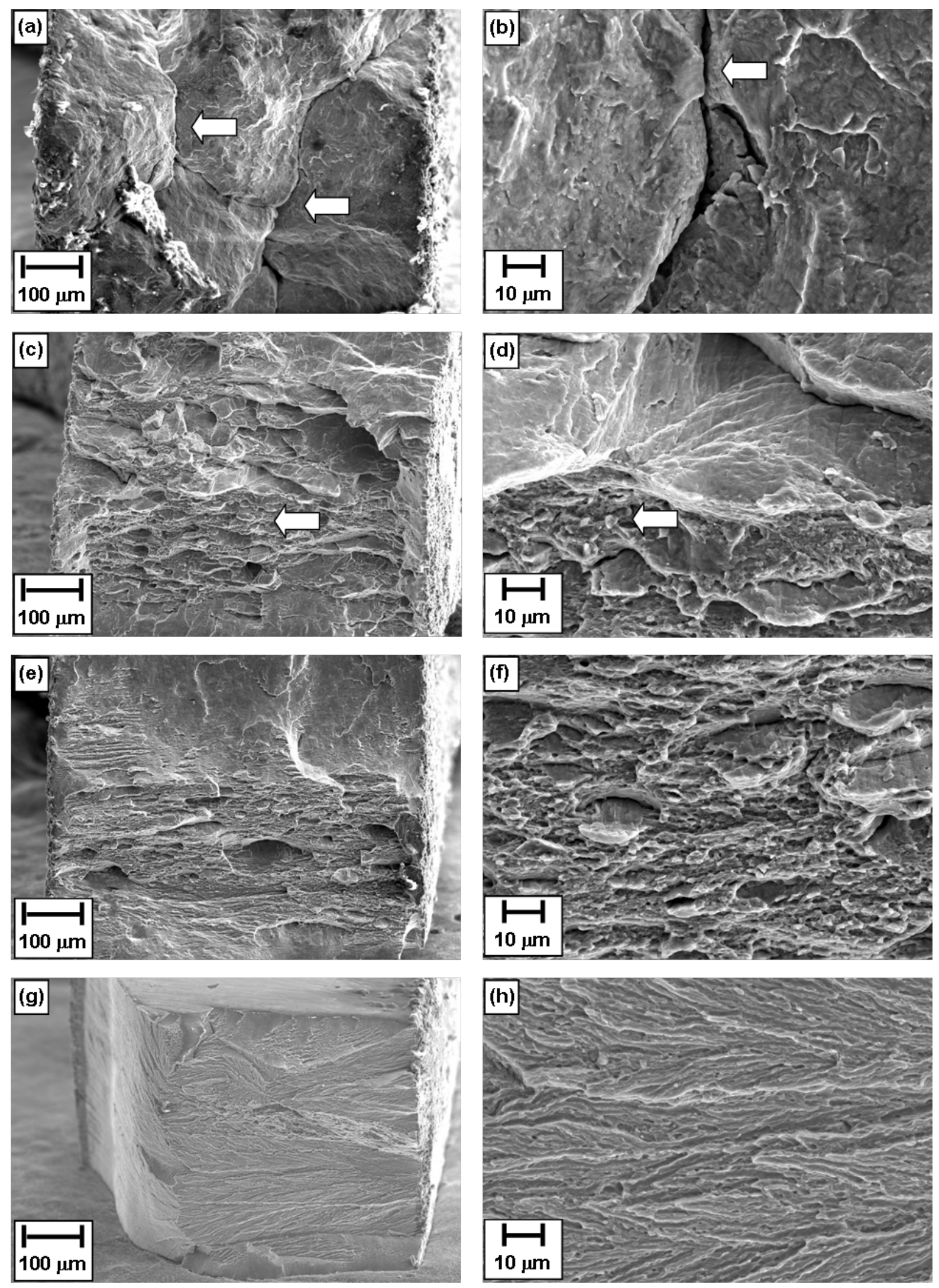

Figure 6. SEM fractographs of samples processed under 2 GPa for $N=$ (a, b) 1, (c, d) 4, (e, f) 10, and (g, h) 40 revolutions. 

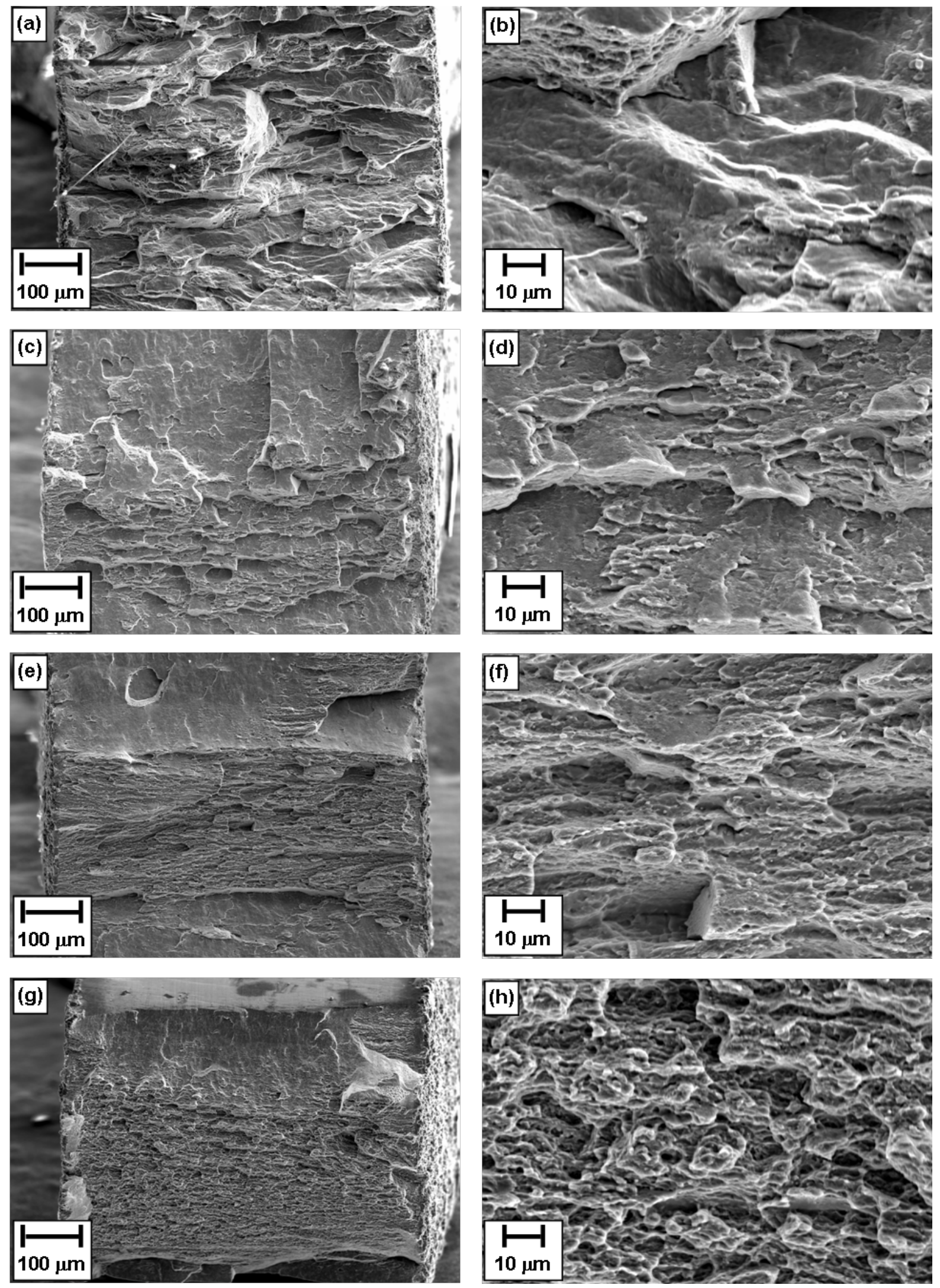

Figure 7. SEM fractographs of samples processed under 6 GPa for $N=(a, b) 1$, (c, d) 4, (e, f) 10, and $(\mathrm{g}, \mathrm{h}) 40$ revolutions. 

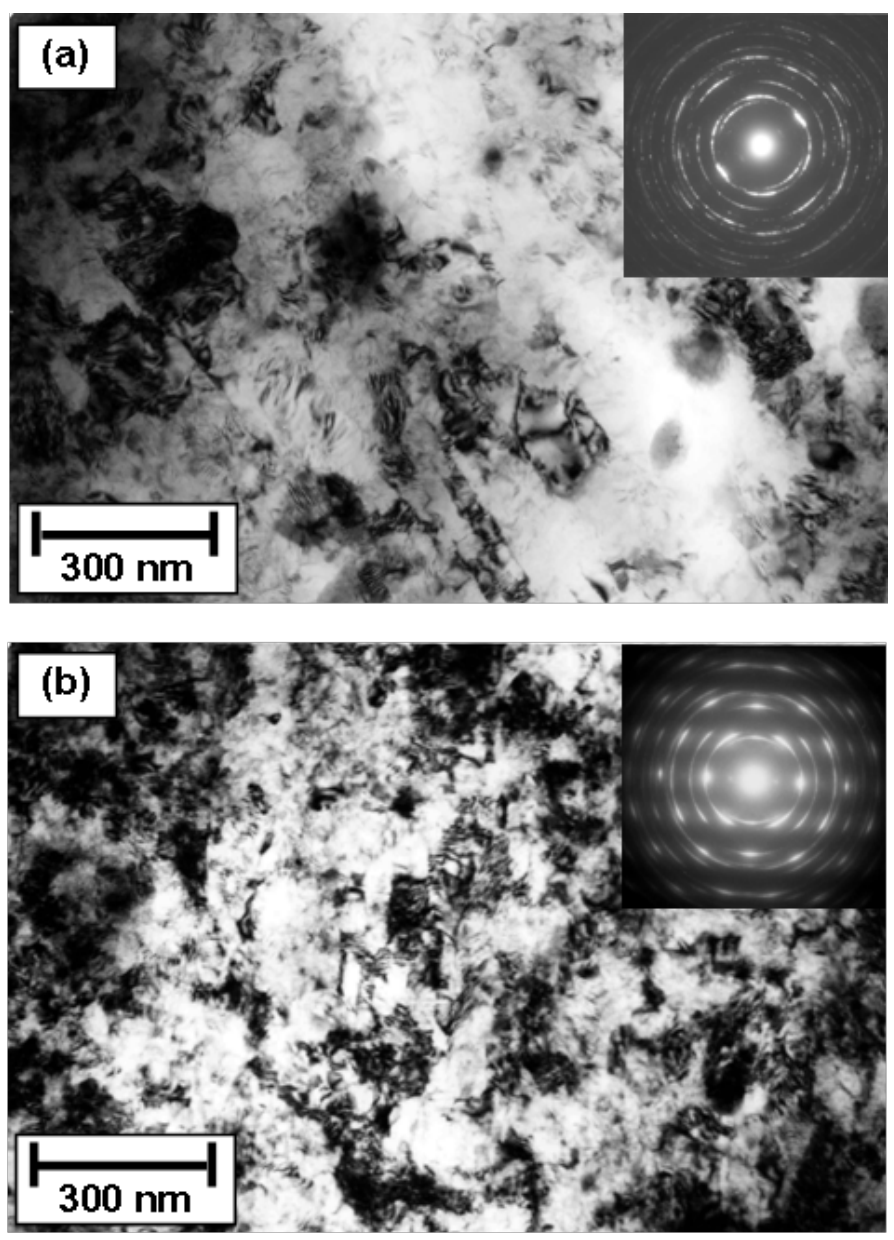

Figure 8. TEM micrographs and SAED patterns of samples processed for: (a) 10 revolutions under 2 GPa with rotation speed of $1.0 \mathrm{rpm}$, (b) 10 revolutions under $6 \mathrm{GPa}$ with rotation speed of $0.2 \mathrm{rpm}$.

Figure 9 shows X-ray profiles for different numbers of revolutions under pressures of (a) 2 GPa and (b) 6 GPa. An examination of Fig. 5 indicates the five important points:

(1) No phase transformation is detected after processing of powders with ball milling even after 50 $\mathrm{h}$ milling and this is not consistent with published papers reporting a formation of $f c c$ Ti during ball milling [37, 38]. The difference must be due to lower milling intensity and less contamination level in this study.

(2) No phase transformation is detected after consolidation of powders with HPT under 2 GPa. However, a peak for the $\omega$ phase clearly appears after HPT for $N=1$ under 6 GPa. This is in good agreement with earlier observations on bulk Ti that an $\alpha \rightarrow \omega$ phase transformation occurs when HPT is operated under pressures higher than 3-4 GPa [43-46].

(3) A comparison between the peak height of $(1011)_{\alpha}$ and $(0002)_{\alpha}$ planes indicates that a texture develops such that the peak height of basal plane decrease with straining. Since the XRD analysis was performed in a direction perpendicular to shear plane, it is concluded that the pyramidal planes of the $\alpha$ phase tend to be parallel to the shear plane and disc surface. 
(4) The peak height of $\omega$ phase increases from $N=1$ to $N=4$ in consistence with earlier works that the fraction of $\omega$ phase increases with increasing strain [43-46]. However, the peak height of $\omega$ phase decreases for $N=10$ and disappears by $N=40$.

(5) For the samples subjected to HPT under $6 \mathrm{GPa}$ for $N=10$, the peak height of $\omega$ phase increases with a decrease in the rotation speed from 1.0 to $0.2 \mathrm{rpm}$.
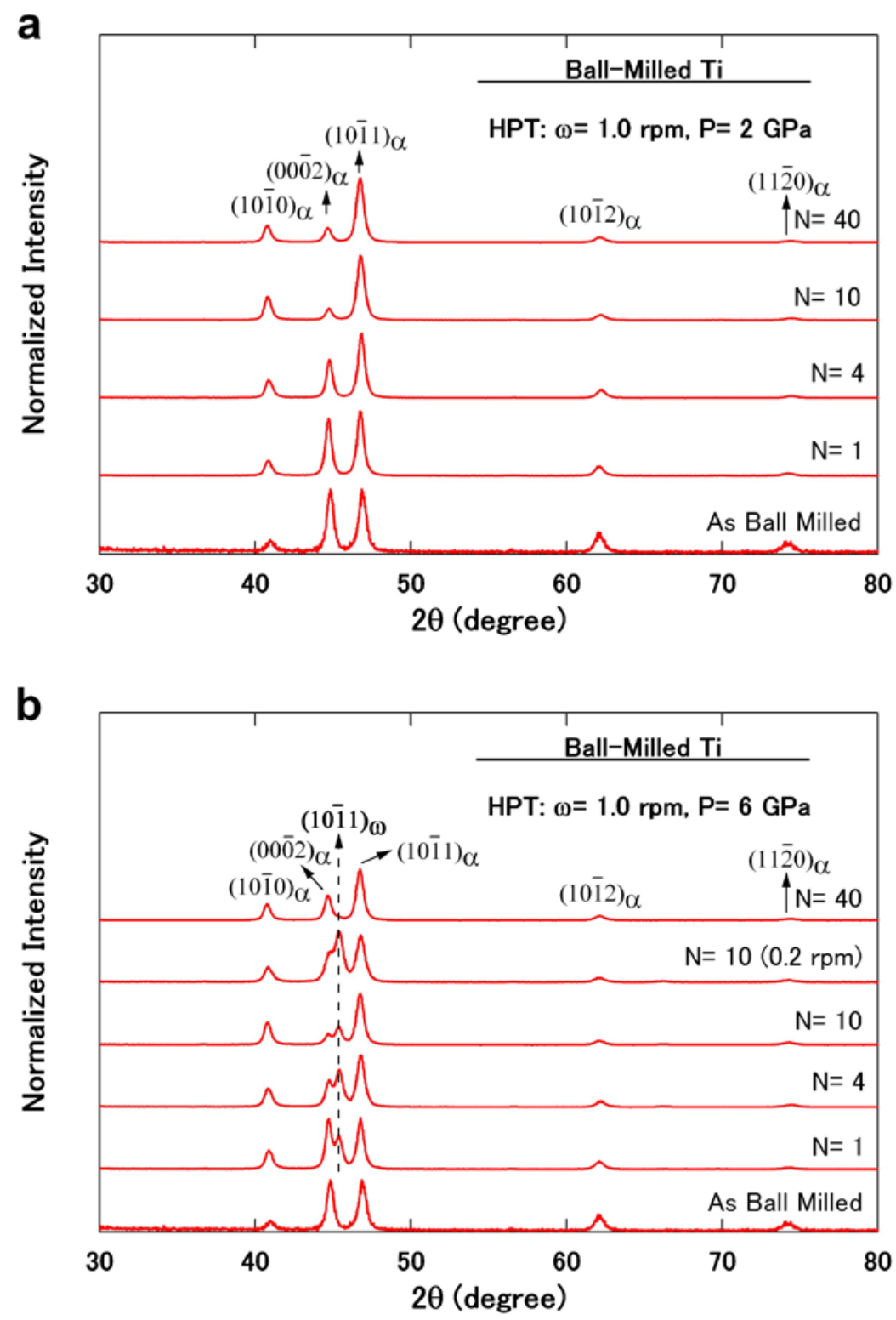

Figure 9. XRD profiles for samples processed after various revolutions under (a) 2 GPa and (b) 6 GPa.

Figure 10 delineates (a) the nominal stress-displacement curves obtained from the bending tests and (b) the nominal stress-strain curves obtained from the tensile tests at room temperature for two reference HPT-processed samples: first, powder sample without ball milling with the purity of 99.9\% and second, a bulk sample with the same purity of $99.9 \%$. Both tensile and bending strengths are higher and tensile and bending ductilities are less for the HPT-consolidated powder samples 
than the bulk samples. The bulk sample processed with HPT bent to a hairpin shape confirming an excellent ductility and this is even comparable with the ductility of the annealed sample, as reported earlier [51].

Density measurement in this study revealed that an average density of $4.543 \pm 0.009$ g.cm ${ }^{-3}$ was obtained after cold consolidation with HPT for 10 revolutions under $2 \mathrm{GPa}$. Since the density for the annealed bulk sample was measured $4.549 \mathrm{~g} . \mathrm{cm}^{-3}$ in this study, a relative density as high as 99.9\% is attained following the HPT, indicating an almost perfect consolidation free of porosity
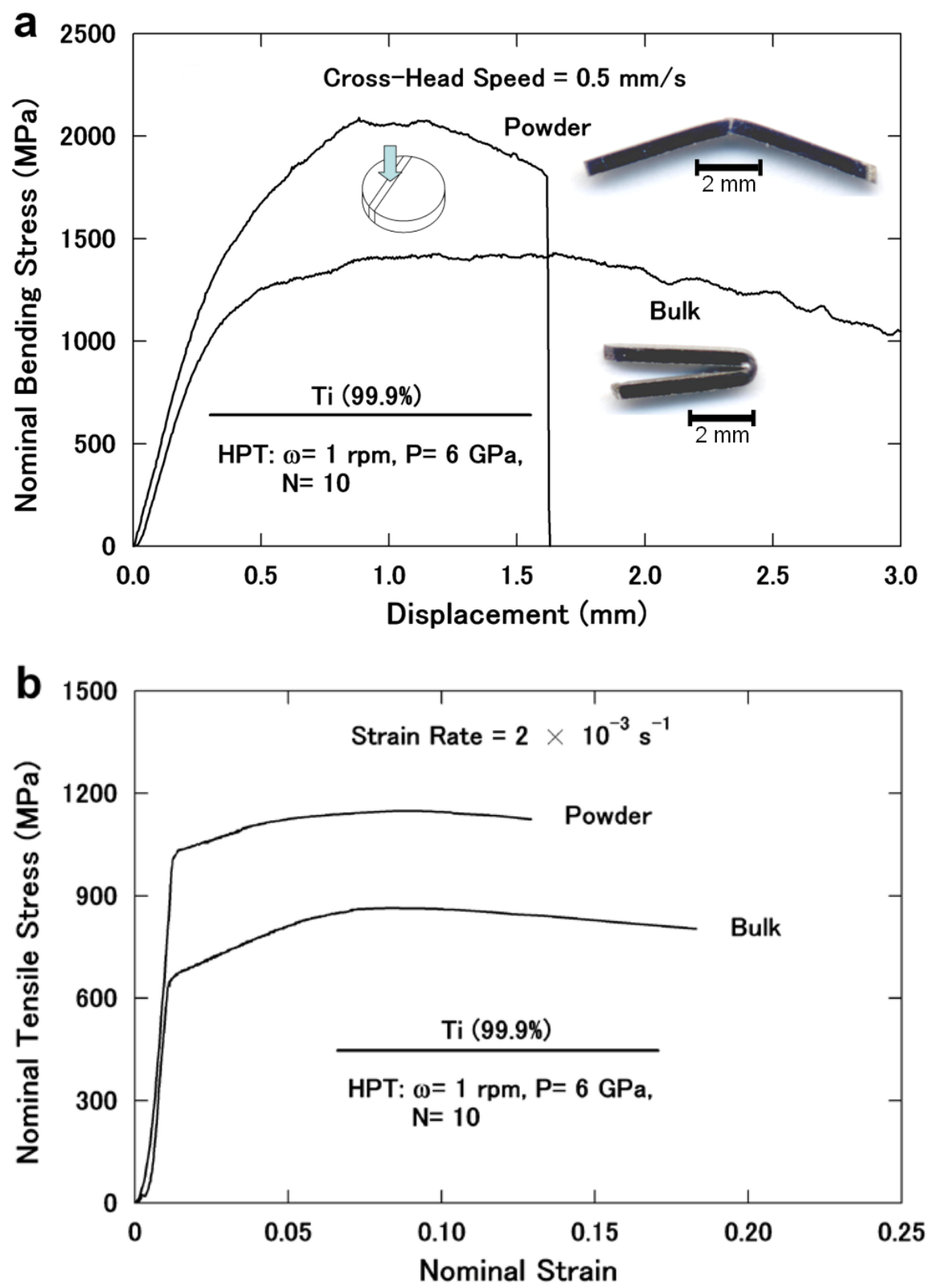

Figure 10. (a) nominal bending stress versus displacement curves in pressing direction and (b) Nominal tensile stress versus nominal strain curves for Ti powders and bulk sample processed for $N=10$ revolutions under $6 \mathrm{GPa}$ with rotation speed of $1.0 \mathrm{rpm}$. 


\section{Discussions}

Earlier studies showed that the hardness variation is represented by a unique function of equivalent strain for bulk samples subjected to HPT [46, 47, 49-54]. The hardness behavior of Ti powders consolidated with HPT, as shown in Fig. 3, is then essentially similar to that of the bulk Ti after HPT [46]. The following two points should be noted from the comparison between the results of bulk and powders after HPT processing.

First, the saturation level at the steady state for the powders is higher than that for the bulk by $\sim 70 \mathrm{Hv}$. It is considered that this difference can be due to contamination oxidation and/or straining during ball-milling process for the powders. To clarify this, additional results for powder and bulk samples without ball milling both with the same purity as 99.9\% was shown in Fig. 10. Both tensile and bending strengths are higher for the HPT-consolidated powder samples than the bulk samples. This indicates that oxide layers on the $\mathrm{Ti}$ powders contribute to an appreciable enhancement of the strength as a reinforcement after consolidation by HPT. These observations are consistent with an earlier paper reporting that the oxidation of the Ni powders has a large effect on the grain refinement, the mechanical properties and the thermal stability of the consolidated material due to pining effect of the oxide particles [21]. When Fig. 10 is compared with Figs. 4 and 5 , the strength of both bending and tensile tests are appreciably higher in the ball-milled powders than in the powders without ball milling. Thus, contamination and/or straining during ball milling appear to be other causes for the enhancement of the strength. It should be noted that HPT was conducted under $6 \mathrm{GPa}$ in this additional experiment, but XRD analysis confirmed that the transformation to $\omega$ phase was not detected because of the rotation speed which is high enough to raise temperature during HPT processing and thus to induce the reverse transformation to $\alpha$ phase as discussed below.

Second, the saturation level of hardness depends not only on the applied pressure but also on the numbers of revolutions and rotation speeds as reported on the bulk [46]. The higher hardness obtained under 6 GPa is due to the formation of the $\omega$ phase through the $\alpha \rightarrow \omega$ phase transformation during HPT processing, as shown in Fig. 9. The formation of the $\omega$ phase and its stability with respect to strain were described in details earlier [46]. The deviation to lower hardness levels shown in Fig. 3(b) must be due to heat generation and a reverse transformation from the $\omega$ phase to the $\alpha$ phase during HPT processing. Because the rotation speed is as high as $1.0 \mathrm{rpm}$ and/or the number of revolutions is as large as $N=10$ and 40 , the heat generation is sufficient enough to introduce the reverse transformation as shown in Fig. 9(b). It was confirmed that the anvil temperature recorded during HPT at $6 \mathrm{GPa}$ reached $331 \mathrm{~K}\left(58{ }^{\circ} \mathrm{C}\right)$ and $354 \mathrm{~K}\left(81{ }^{\circ} \mathrm{C}\right)$ for 10 and 40 revolutions, respectively, with a rotation speed of $1.0 \mathrm{rpm}$. Considering the fact that the thermocouple was located $10 \mathrm{~mm}$ away from the sample, it is reasonable that the sample temperature may be increased enough to cause an reverse phase transformation and thus to lower the hardness. For the sample processed under $6 \mathrm{GPa}$ for $N=10$ with a rotation speed of $0.2 \mathrm{rpm}$, heat generation was insignificant and thus the temperature reached $307 \mathrm{~K}\left(34{ }^{\circ} \mathrm{C}\right)$ which were not high enough for the reverse transformation. Therefore, the peak height for the $\omega$ phase, as shown in Fig. 9(b), and the hardness level, as shown in Fig. 3(a), are well higher for the rotation speed of $0.2 \mathrm{rpm}$ than that of 


\section{$1.0 \mathrm{rpm}$.}

The results of bending and tensile tests shown in Figs. 4 and 5 demonstrate that high strength and reasonable ductility are achieved after cold consolidation of powders using HPT. The lower ductility for the samples processed at $6 \mathrm{GPa}$ in Fig. 5(b) must be a result of the $\omega$-phase formation which is more brittle than the $\alpha$ phase. Examination of Figs. 5, 6 and 7 indicates the following two important points. First, the highest ductility and strength as well as the finest dimple-like pattern fracture surface is achieved for the sample subjected to 40 revolutions under 6 GPa. Therefore, the transformation of $\alpha$ phase to $\omega$ phase and the full reverse transformation of $\omega$ phase to $\alpha$ phase lead to promising mechanical properties in HPT-consolidated ball-milled Ti. Similar behavior is expected for the bulk sample following HPT under $6 \mathrm{GPa}$ and large numbers of revolutions or following post-HPT annealing at temperatures slightly higher than the reverse transformation temperature from $\omega$ phase to $\alpha$ phase (> $423 \mathrm{~K}\left(150^{\circ} \mathrm{C}\right)$ [46]). Second, the numbers of revolutions for achieving the maximum strength and ductility is 10 under $2 \mathrm{GPa}$, as shown in Fig. 5(a), indicating that the consolidation is completed after 10 revolutions. However, the maximum strength is achieved after 4 revolutions under $6 \mathrm{GPa}$ as in Fig. 5(b). Therefore, higher applied pressure gives rise to more expeditious consolidation in consistence with earlier reports that a higher density is achieved at higher pressures for composite powders [11, 12]. For the sample consolidated with HPT for $N=40$ under $2 \mathrm{GPa}$, the sample fractured in a brittle manner despite the fact that the sample contains no $\omega$ phase. Optical microscopy observations indicate that this brittle fracture can be due to the formation of cracks during processing by HPT for $N=40$ as reported in a Mg alloy [55].

Figure 11 shows summary of the tensile tests after ball milling followed by HPT of Ti powders together with relevant published data for comparison [41, 46, 56-58]. The published data include those after annealing, cold rolling or hot rolling of bulk $\mathrm{Ti}[41,46]$ and of bulk Ti-6\%Al-4\%V [41], HPT of bulk Ti under 2 and 6 GPa [46], equal-channel angular pressing (ECAP) of bulk Ti for 8 passes [56, 57], ECAP followed by cold rolling or cold extrusion [56, 57], accumulative roll-bonding (ARB) of bulk Ti for 8 passes [58] and of ball milling (BM) followed by hot roll sintering of Ti powders [41]. Solid line represents a relation delineated through the points obtained by the annealed sample and conventional cold-rolled and hot-rolled samples for bulk Ti. It should be noted that, as pointed out by Zhao et al. [59], care is required for this comparison because the ratios of the gauge length to the gauge width are varied from 1 to 5 . There is a trade-off relation between the strength and the elongation to failure for all data points plotted in Fig. 11. However, HPT processing in the optimized conditions ( $N=40$ under $6 \mathrm{GPa}$ and $N=10$ under $2 \mathrm{GPa}$ ) provides important advantages over hot roll sintering. First, the strength of pure Ti is significantly enhanced so that it becomes comparable to the strength of $\mathrm{Ti}-6 \% \mathrm{Al}-4 \% \mathrm{~V}$ after severe plastic deformation with even better ductility when ball-milled powders are used, second bulk Ti increases its strength over the strength of Ti ball-milled and sintered powders, and third, HPT processing can successfully achieve dense consolidation without requiring neither heating of the powders nor of the processing system. It is found that Ti processed by ball-milling followed by HPT shows the highest strength when compared to other processing methods as shown in Fig. 11. 


\section{Summary and conclusions}

Ball-milled pure Ti powders were consolidated by high-pressure torsion (HPT) and the following conclusions were obtained.

1. The hardness variation can be represented as a unique function of equivalent strain for powders consolidated with HPT.

2. A relative density as high as $99.9 \%$, a high tensile strength of $1.35 \mathrm{GPa}$, a reasonable ductility of $8 \%$ and an average grain size of $\sim 150 \mathrm{~nm}$ are achieved after cold consolidation using HPT for 10 revolutions.

3. In HPT processing, higher applied pressure and strain give rise to more expeditious consolidation.

4. A phase transformation occurs from $\alpha$ phase to $\omega$ phase during HPT under 6 GPa whereas no phase transformation is detected after processing with ball milling alone.

5. Transformation of $\alpha$ phase to $\omega$ phase and full reverse transformation of $\omega$ phase to $\alpha$ phase improves the mechanical properties of consolidated powders.

6. Both strength and ductility of pure Ti processed with ball milling followed by HPT are well comparable to those of $\mathrm{Ti}-6 \% \mathrm{Al}-4 \% \mathrm{~V}$ after severe plastic deformation, indicating no requirement of alloying elements.

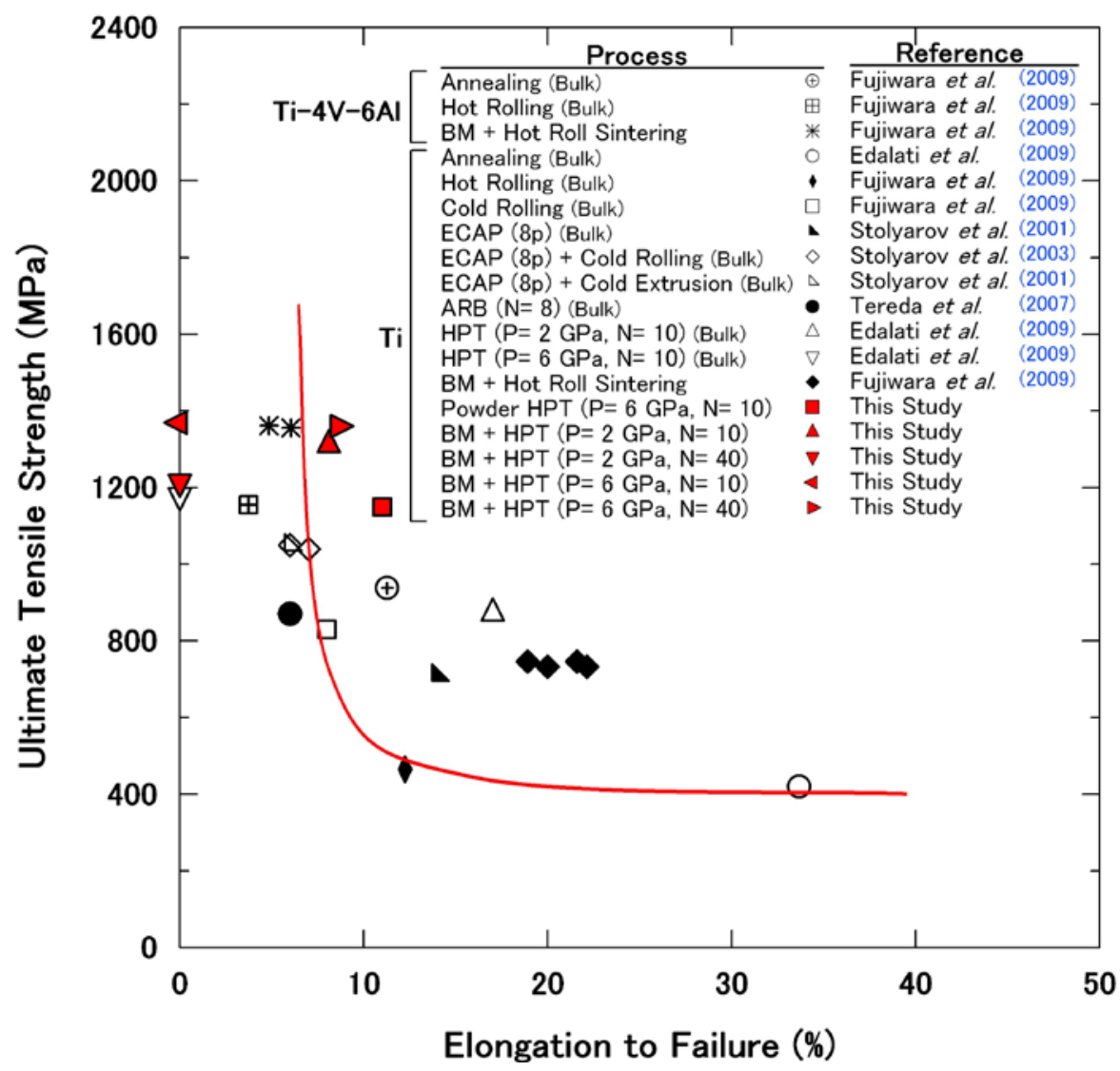

Figure 11. Plots of ultimate tensile strength versus elongation to failure including published data for samples of pure Ti and Ti-6\%Al-4\% V after processing with different methods [41, 46, 56-58]. 


\section{Acknowledgements}

We would like to thank Prof. Kenji Higashida of Kyushu University for permitting the use of the bending test facility and Dr. Masaki Tanaka of Kyushu University for helpful assistance in using a bending test machine. We are also grateful to Prof. H. Miura of Kyushu University for lending us a facility of the density measurement. One of the authors (KE) thanks the Islamic Development Bank for a scholarship. This work was supported in part by a Grant-in-Aid for Scientific Research from the Ministry of Education, Culture, Sports, Science and Technology of Japan in the Priority Area "Giant Straining Process for Advanced Materials Containing Ultra-High Density Lattice Defects" and in part by Kyushu University Interdisciplinary Programs in Education and Projects in Research Development (P\&P).

\section{References}

1. R.Z. Valiev, R.K. Islamgaliev and I.V. Alexandrov: Prog. Mater. Sci., 2000, vol. 45, pp. 103-189

2. A.V. Korznikov, I. Safarov, D.V. Laptionok and R.Z. Valiev: Acta Metal. Mater., 1991, vol. 39, pp. 3193-3197.

3. V.A. Zilbershtein, N.P. Chistotina, A.A. Zharov, N.S. Grishina and E.I. Estrin: Fiz. Metal. Metalloved., 1975, vol. 39, pp. 445-447.

4. P.W. Bridgman, Phys. Rev., 1935, vol. 48, pp. 825-847.

5. H. Shen, B. Guenther, A.V. Koanikov and R.Z. Valiev: Nunostruct. Mater., 1995, vol. 6, pp. 385-388.

6. R.Z. Valiev, R.S. Mishra, J. Groza and A.K. Mukherjee: Scripta Mater., 1996, vol. 34, pp. 1443-1448.

7. J. Sort, A.P. Zhilyaev, M. Zielinska, J. Nogues, S. Surinach, J. Thibault and M.D. Baro: Acta Mater., 2003, vol. 51, pp. 6385-6393.

8. Z. Lee, F. Zhou, R.Z. Valiev, E.J. Lavernia and S.R. Nutt: Scripta Mater., 2004, vol. 51, pp. 209-214.

9. I.V. Alexandrov, Y.T. Zhu, T.C. Lowe, R.K. Islamgaliev and R.Z. Valiev: Nanostruct. Mater., 1998, vol. 10, pp. 45-54.

10. I.V. Alexandrov, Y.T. Zhu, T.C. Lowe and R.Z. Valiev: Powder Metall., 1998, vol. 41, pp. 11-13.

11. I.V. Alexandrov, Y.T. Zhu, T.C. Lowe, R.K. Islamgaliev and R.Z. Valiev: Metall. Mater. Trans. A, 1998, vol. 29, pp. 2253-2260.

12. V.V. Stolyarov, Y.T. Zhu, T.C. Lowe, R.K. Islamgaliev and R.Z. Valiev: Mater. Sci. Eng. A, 2000, vol. 282, pp. 78-85.

13. R. Kuzel, Z. Matej, V. Cherkaska, J. Pesicka, J. Cizek, I. Prochazka and R.K. Islamgaliev: J. Alloys Compd., 2004, vol. 378, pp. 242-247.

14. R.K. Islamgaliev, W. Buchgraber, Y.R. Kolobov, N.M. Amirkhanov, A.V. Sergueeva, K.V. Ivanov and G.P. Grabovetskaya: Mater. Sci. Eng. A, 2001, vol. 319-321, pp. 872-876.

15. T. Tokunaga, K. Kaneko and Z. Horita: Mater. Sci. Eng. A, 2008, vol. 490, pp. 300-304.

16. T. Tokunaga, K. Kaneko, K. Sato and Z. Horita: Scripta Mater., 2008, vol. 58, pp. 735-738.

17. E. Menendez, J. Sort, V. Langlais, A. Zhilyaev, J.S. Munoz, S. Surinach, J. Nogues and M.D. Baro: J. Alloys Comp., 2007, vol. 434-435, pp. 505-508.

18. E. Menendez, G. Salazar-Alvarez, A.P. Zhilyaev, S. Surinach, M.D. Baro, J. Nogues and J. Sort, Adv. Funct. Mater., 2008, vol. 18, pp. 3293-3298.

19. H. Li, A. Misra, Y. Zhu, Z. Horita, C.C. Koch, T.G. Holesinger: Mater. Sci. Eng. A, 2009, vol. 523, pp. 60-64.

20. H. Li, A. Misra, Z. Horita, C.C. Koch, N.A. Mara, P.O. Dickerson, Y. Zhu: J. Appl. Phys., 2009, vol. 95, p. 071907.

21. A. Bachmaier, A. Hohenwartera and R. Pippana: Scripta Mater., 2009, vol. 61, pp. 1016-1019.

22. W.J. Botta Filho, J.B. Fogagnolo, C.A.D. Rodrigues, C.S. Kiminami, C. Bolfarini and A.R. Yavari: Mater. Sci. Eng. A, 2004, vol. 375-377, pp. 936-941.

23. J. Sort, D.C. Ile, A.P. Zhilyaev, A. Concustell, T. Czeppe, M. Stoica, S. Surinach, J. Eckert and M.D. Baro: Scripta Mater., 2004, vol. 50, pp. 1221-1225.

24. A.R. Yavari, W.J. Botta Filho, C.A.D. Rodrigues, C. Cardoso and R.Z. Valiev: Scripta Mater., 2002, vol. 
46, pp. 711-716.

25. Z. Kovacs, P. Henits, A.P. Zhilyaev and A. Revesz: Scripta Mater., 2006, vol. 54, pp. 1733-1737.

26. N. Boucharat, R. Hebert, H. Rosner, R.Z. Valiev and G. Wilde: J. Alloys Compd., 2007, vol. 434-435, pp. 252-254.

27. T. Czeppe, G. Korznikova, J. Morgiel, A. Korznikov, N.Q. Chinh, P. Ochin and A. Sypien: J. Alloys Compd., 2009, vol. 483, pp. 74-77.

28. K. Edalati, Y. Yokoyama and Z. Horita: Mater. Trans., 2010, vol. 51, pp.23-26.

29. A.P. Zhilyaev, A.A. Gimazov, G.I. Raab and T.G. Langdon: Mater. Sci. Eng. A, 2008, vol. 486, pp. 123-128.

30. A.P. Zhilyaev, S. Swaminathan, A.A. Gimazov, T.R. McNelley and T.G. Langdon: J. Mater. Sci., 2008, vol. 43, pp. 7451-7456.

31. K. Edalati and Z. Horita: Scripta Mater., 2010, Vol. 63, pp. 174-177.

32. J.S. Benjamin: Sci. Amer., 1976, vol. 234, pp. 40-48.

33. C. Suryanarayana: Prog. Mater. Sci., 2001, vol. 46, pp. 1-184.

34. ASM Handbook, vol. 7, Powder Metal Technologies and Applications, 10th ed., ASM International, Metals Park, Ohaio, 1998.

35. C.J. Lu, J. Zhang and Z.Q. Li: J. Alloys Compd., 2004, vol. 381, pp. 278-283.

36. Y.Y. Li, C. Yang, W.P. Chen, X.Q. Li and M. Zhu: J. Mater. Res., 2007, vol. 22, pp. 1927-1932.

37. P. Chatterjee and S.P. Sen Gupta: Philos. Mag. A, 2001, vol. 81, pp. 49-60.

38. I. Manna, P.P. Chattopadhyay, P. Nandi, F. Banhart and H.J. Fecht: J. Appl. Phys., 2003, vol. 93, pp. 1520-1524

39. J. Dutkiewicz, J. Kusnierz, M. Maziarz, M. Lejkowska, H. Garbacz, M. Lewandowska, A. Dobromyslov and K.J. Kurzydlowski: Phys. Status Solidi A, 2005, vol. 202, pp. 2309-2320.

40. F. Sun, A. Zuniga, P. Rojas and E.J. Lavernia: Metall. Mater. Trans. A, 2006, vol. 37, pp. 2069-2078.

41. H. Fujiwara, T. Sekiguchi and K. Ameyama: Int. J. Mater. Res., 2009, vol. 100, pp. 796-799.

42. Y. K. Vohra, S.K. Sikka, S.N. Vaidya and R. Chidamberan: J. Phys. Chem. Solids, 1977, vol. 38(11), pp. 1293-1296.

43. A.R. Kilmametov, A.V. Khristoforova, G. Wilde and R.Z. Valiev: Z. Kristallogr. Suppl., 2007, vol. 26, pp. 339-344.

44. Y. Ivanisenko, A. Kilmametov, H. Rosner and R.Z. Valiev: Int. J. Mater. Res., 2008, vol. 99, pp. 36-41.

45. Y. Todaka, J. Sasaki, T. Moto and M. Umemoto: Scripta Mater., 2008, vol. 59, pp. 615-618.

46. K. Edalati, E. Matsubara and Z. Horita: Metall. Mater. Trans. A, 2009, vol. 40, pp. 2079-2086.

47. K. Edalati, Z. Horita, S. Yagi and E. Matsubara: Mater. Sci. Eng. A, 2009, vol. 523, pp. 277-281.

48. ASTM E290, Standard Test Methods for Bend Testing of Material for Ductility, ASTM International, West Conshohocken, PA, 2009.

49. K. Edalati, Z. Horita and T.G. Langdon: Scripta Mater., 2009, vol. 60, pp. 9-12.

50. K. Edalati, T. Fujioka and Z. Horita: Mater. Trans., 2009, vol. 50, pp. 44-50.

51. K. Edalati, Z. Horita, M. Tanaka and K. Higashida: Adv. Mater. Res., 2010, vol. 89-91, pp. 171-176.

52. A. Vorhauer and R. Pippan: Scripta Mater., 2004, vol. 51, pp. 921-925.

53. K. Edalati, T. Fujioka and Z. Horita: Mater. Sci. Eng. A, 2008, vol. 497, pp. 168-173.

54. K. Edalati, Z. Horita and Y. Mine: Mater. Sci. Eng. A, 2010, vol. 527, pp. 2136-2141.

55. M. Kai, Z. Horita and T. G. Langdon: Mater. Sci. Eng. A, 2008, vol. 488, pp. 117-124.

56. V.V. Stolyarov, Y.T. Zhu, T.C. Lowe and R.Z. Valiev: Mater. Sci. Eng. A, 2001, vol. 303 pp. 82-89.

57. V.V. Stolyarov, Y.T. Zhu, I.V. Alexandrov, T.C. Lowe and R.Z. Valiev: Mater. Sci. Eng. A, 2003, vol. 343, pp. 43-50.

58. D. Terada, S. Inoue and N. Tsuji: J. Mater. Sci., 2007, vol. 42, pp. 1673-1681.

59. Y.H. Zhao, Y.Z. Guo, Q. Wei, A.M. Dangelewicz, C. Xu, Y.T. Zhu, T.G. Langdon, Y.Z. Zhou and E.J. Lavernia: Scripta Mater., 2008, vol. 59, pp. 627-630. 